\title{
SOCIAL DISTANCING AND SOCIAL CAPITAL: WHY U.S. COUNTIES RESPOND DIFFERENTLY TO COVID-19
}

\author{
Wenzhi Ding \\ Ross Levine \\ Chen Lin \\ Wensi Xie \\ Working Paper 27393 \\ http://www.nber.org/papers/w27393 \\ NATIONAL BUREAU OF ECONOMIC RESEARCH \\ 1050 Massachusetts Avenue \\ Cambridge, MA 02138 \\ June 2020
}

The views expressed herein are those of the authors and do not necessarily reflect the views of the National Bureau of Economic Research.

NBER working papers are circulated for discussion and comment purposes. They have not been peer-reviewed or been subject to the review by the NBER Board of Directors that accompanies official NBER publications.

(C) 2020 by Wenzhi Ding, Ross Levine, Chen Lin, and Wensi Xie. All rights reserved. Short sections of text, not to exceed two paragraphs, may be quoted without explicit permission provided that full credit, including $(\odot$ notice, is given to the source. 
Social Distancing and Social Capital: Why U.S. Counties Respond Differently to COVID-19 Wenzhi Ding, Ross Levine, Chen Lin, and Wensi Xie

NBER Working Paper No. 27393

June 2020

JEL No. D62,H12,H41,I18

\section{ABSTRACT}

Since social distancing is the primary strategy for slowing the spread of many diseases, understanding why U.S. counties respond differently to COVID-19 is critical for designing effective public policies. Using daily data from about 45 million mobile phones to measure social distancing we examine how counties responded to both local COVID-19 cases and statewide shelter-in-place orders. We find that social distancing increases more in response to cases and official orders in counties where individuals historically (1) engaged less in community activities and (2) demonstrated greater willingness to incur individual costs to contribute to social objectives. Our work highlights the importance of these two features of social capitalcommunity engagement and individual commitment to societal institutions-in formulating public health policies.

Wenzhi Ding

University of Hong Kong

Hong Kong

wenzhi.ding@connect.hku.hk

Ross Levine

Haas School of Business

University of California at Berkeley

545 Student Services Building, \#1900 (F685)

Berkeley, CA 94720-1900

and NBER

Ross_levine@haas.berkeley.edu
Chen Lin

Faculty of Business and Economics

The University of Hong Kong

Hong Kong

chenlin1@hku.hk

Wensi Xie

Department of Finance

Chinese University of Hong Kong

Hong Kong

wensixie@cuhk.edu.hk 


\section{INTRODUCTION}

U.S. communities have responded very differently to the COVID-19 pandemic. Data from about 45 million phones indicates that the proportion of people staying at home during the typical day in the average U.S. county grew by $42 \%$ from February to April 2020 with a crosscounty standard deviation of $23 \%$, highlighting the enormous heterogeneity in the degree to which people socially distanced in response to the pandemic. Since social distancing is the primary strategy for slowing the spread of many diseases, understanding the sources of these differences is critical for designing and implementing effective public policies for this and future public health emergencies.

At a broad level, social capital theory offers clear predictions about the provision of public goods and hence about cross-county differences in the extent to which people socially distanced in response to the COVID-19 pandemic. Social capital refers to the shared values, accepted norms, reciprocal bonds, and trust among a group of individuals that allow individuals within that group to communicate and cooperate to help its members and address collective challenges (e.g., Loury 1977; Bourdieu 1986; Coleman 1988; Fukuyama 1995; Putnam 2000). Accordingly, social capital is a resource that helps communities provide public goods, including by facilitating collaborative actions to bolster public health (e.g., House et al. 1988; Pretty 2003; Snyder-Mackler et al 2020).

At a more granular level, however, it is critical to distinguish between two distinct features of social capital indicators in formulating predictions social distancing One category of social capital indicators focuses on community engagement. Putnam (2000) famously highlighted bowling teams in making the broad point that people's engagement in community activitiesincluding sports teams, clubs, religious, groups, civic organization, etc.- provides information on the community's ability to cooperate and provide public goods. For the special case of social distancing as public good, however, community engagement suggests that people will find it more costly to separate from these highly-valued social connections. From this perspective, counties with stronger community engagement will tend to engage in less - not more - social distancing in 
response to the pandemic. The second category of social capital indicators focuses on individual commitment to social institutions, which Guiso, Sapienza, and Zingales (2011) and Barrios et al. (2020) call civic capital. The intuition is that when people demonstrate that they are willing and able to incur a cost to contribute to societal objectives, such as voting, completing census forms, donating blood, etc., this provides information about the community's ability to marshal its individuals to address collective problems. From this perspective, when individual commitment to broader social objectives is stronger in a community, the community is likely to exhibit greater social distancing in response to the COVID-19 pandemic. Thus, the community engagement and individual commitment to social institutions features of social capital might exert opposite effects on social distancing.

In this paper, we examine the degree to which social capital characteristics - as measured both by community engagement and individual commitment to social institutions - account for differences in social distancing across U.S. counties in response to the COVID-19 pandemic. To measure social distancing in each county, we use daily data from January 22, 2020 through the end of April 2020 on the percentage of mobile phones that do not leave home. We use two daily indicators of a county's "exposure" to the pandemic: the number of confirmed COVID-19 cases in the county during the previous week, and the number of social distancing orders (SDOs) imposed by the county's state, e.g., orders to stay home, avoid social gathering, close schools, close restaurants, close other non-essential businesses. Since local COVID-19 cases and SDOs might each induce social distancing, we examine how a county's social capital shapes its social distancing response to both new local cases and SDOs. To measure social capital, we use prepandemic county-level data collected by the U.S. Congress and Penn State's Northeast Regional Center for Rural Development. Although much of the empirical research on social capital uses only aggregate social capital indexes, we examine both the aggregate indexes and the individual components to assess the different predictions concerning the community engagement and individual commitment to social institutions features of social capital. 
We discover strong evidence that (1) social capital helps account for cross-county differences in social distancing, but (2) it is essential to distinguish between community engagement and individual commitment to social institutions indicators of social capital and not simply use overall indexes. Specifically, the sensitivity of social distancing to both local COVID-19 cases and statewide mobility restrictions is (a) weaker in counties with stronger community engagement and hence with greater costs to social distancing and (a) stronger in counties with stronger individual commitment and hence where individuals internalize the social benefits of social distancing. In contrast, the findings on overall composite social capital indexes are fragile and inconsistent. Only by examining the individual features of social capital indicators does a clear pattern emerge: When communities are heavily engaged in community activities, it is specially costly to disengage from these human connections and socially distance; and, when individuals are more committed to contributing to social goals, they are more willing to incur the costs and inconveniences of social distancing to contribute to public objectives. Both community engagement and individual commitment are features of social capital, but they exert opposite influences on social distancing.

\section{DATA AND PATTERNS}

\subsection{Data sources and definition}

We use U.S. county-level data on social distancing, social capital, COVID-19 cases, and other country traits and state-level data on social distancing orders (SDOs) to examine how the relationships between social distancing and both COVID-19 cases and SDOs differ by social capital. In this section, we describe the key data sources and variables and illustrate patterns across the U.S. counties. Table 1 provides summary statistics.

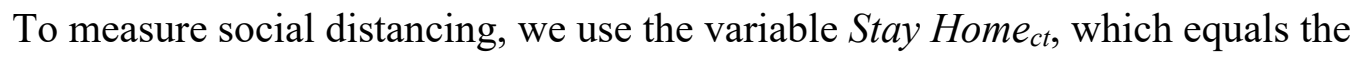
percentage of mobile devices in county $c$ on day $t$ that do not leave home, where "home" is defined as the most common nighttime location of the device in recent months and is identified 
to a precision of 100 square meters. ${ }^{1}$ We obtain this information from the data company, SafeGraph, that has provided mobility data to researchers since the onset of the COVID-19 pandemic. Working with mobile applications that obtain opt-in consent from users to collect anonymous location data, SafeGraph obtains information from about 45 million mobile smartphones.

To measure local exposure to COVID-19, we use Cases $_{c t}$, which equals is the natural logarithm of one plus the number of new COVID-19 cases in county c during the week before day $t$, i.e., from $t-7$ through $t-1$. The Center for Systems Science and Engineering at Johns Hopkins University provides these data.

To measure SDOs, we use information on statewide mobility restrictions. U.S. states enacted different SDOs at different times. They instituted five categories of SDOs: stay-at-home orders, the closing of restaurants and bars, the closing of other non-essential businesses, limits on social gatherings, and the closing of schools. We use the measure Restrictions $s_{\text {st }}$ which equals the total number of the five categories of SDOs in place on day $t$ in state $s$.

To measure social capital, we use eight county-level measures that were computed before the COVID-19 pandemic by two sources: the U.S. Congress (Joint Economic Committee) and Penn State's Northeast Regional Center for Rural Development (e.g., Rupasingha, Goetz, and Freshwater 2006). The four U.S. Congress social capital measures are as follows.

Social capital (US Congress) is an overall index of social capital that aggregates information on three subcomponents: (1) family unity, (2) community health, i.e., community cohesion and engagement, and (3) institutional health, i.e., trust and confidence in institutions.

\footnotetext{
${ }^{1}$ The results reported below are robust to using several alternative measures of social distancing provided by SafeGraph. We considered three variants of Stay Home. Stay Home (non-FT) is the same as Stay Home except that it excludes devices owned by a full-time workers and Stay Home (non-working) excludes devices owned by a full-time worker or part-time worker. Stay Home (Diff) is the percentage change in Stay Home relative to the pre-pandemic average, which is the average percent of devices staying at home each day during the seven days ending February 12, 2020. Furthermore, we considered visits non-essential businesses, such as restaurants and bars, stores and shopping malls, theaters, and spas, hair salons, personal care services. The results hold when using these measures.
} 
Community health measures the degree to which individuals engage in community activities. It includes information the number of non-religious non-profits organizations, religious congregations, and the degree of community involvement in informal social activities such as attending public meetings, helping neighbors, and taking part in political affairs

Institutional health measures commitment to society and trust in institutions. It includes information on the proportion of the voting age population that voted in 2012 and 2016 presidential elections, the response rate to the 2010 census, and survey-based indicators of the degree of confidence in institutions.

Family unity measures family structure and stability within a county and includes information on the share of births in the past year to women who were unmarried, the share of women between 33 and 45 years old who are currently married and not separated, and the share of children living in single-parent households.

The four Penn State social capital measures are as follows:

Social capital (Penn State) is an overall index of social capital at the county level that aggregates information on community activities and commitment to society, such as participation in the presidential election and the response rate to the Census Bureau's decennial census.

Associations (normalized) is an index of the combined number of (a) establishments related to community activities and (b) non-profit organizations (excluding internationally-focused NPOs) per 1,000 people. ${ }^{2}$ Establishments related to community

\footnotetext{
${ }^{2}$ To calculate normalized association index, we (1) compute the min-max scaled version of the number of establishments per 1,000 people in a county, (2) compute the min-max scaled version of number of non-profit organization per 1,000 people in a county, and (3) compute the average of these two scaled versions. We use the normalized values because there are many fewer non-profit organizations. Appendix Table 1 provides the details of this calculation. The results hold when simply using the total number of community and non-profit establishments.
} 
activities include sports teams, clubs, and bowling teams, as well as religious, civic, business, professional, labor, and political establishments.

Voter turnout is the percentage of people who voted in the 2012 Presidential election relative to eligible voters.

Census response is the proportion of households that responded to the 2010 Census. U.S. states instituted SDOs as COVID-19 spread across the United States.

The analyses employ data on four other county traits. The first three traits are measured prior to the pandemic: $\log$ (income per capita) is the natural logarithm of personal income per capita; Population density equals the number of people per square mile; and \%aged $65+$ is the percentage of the population that is over 65 years. The fourth trait, Days since $1^{s t}$ case, equals the number of days since the county had its first confirmed case of COVID-19.

\subsection{Patterns}

Figures 1 and 2 illustrate the geographic distribution of COVID-19 cases. When examining the cumulative number of confirmed COVID-19 cases in each county through April 30, 2020, Figure 1 illustrates a concentration of cases in the northeast and several urban areas across the country. When focusing on cases per 100,000 people, Figure 2 documents a more even distribution of the disease.

Figure 3 documents the degree of social distancing, as measured by Stay Home on April 30,2020 . As shown, there is extensive heterogeneity in the degree to which mobile devices spend that day at home across U.S. counties. Stay Home on April 30, 2020 is greatest in the North East, smallest in much of the South and Plains, higher along the West Coast and in the Rocky Mountain states than in other parts of the country. It is also crucial to note that Stay Home differs materially across counties within states.

Figures 4-9 illustrate the enormous cross-county heterogeneity in social capital as measured by Community health, Institutional health, Associations, Voter turnout, Census 
response, and Family unity respectively. For example, consider two subcomponents from the U.S. Congress social capital index: Community health, which measures community engagement (Figure 4), and Institutional health, which measures individual commitment to social institutions (Figure 5). As shown, there are regional differences in Community health and Institutional health and even differences across counties within states. We exploit this heterogeneity in examining cross-county responses to COVID-19.

We next illustrate the evolution of Stay Home from January 22, 2020 through April 30, 2020 while differentiating between counties with high or low social capital. Specifically, for each of the individual social capital indicators, we divide counties into those in the top and bottom quartiles of social capital, using the term "high" for the top quartile and "low" for the bottom by the sample median and categorize the counties as high or low. We then plot the evolution of Stay Home for high and low counties for each individual social capital indicator (Community health, Institutional health, Associations, Voter turnout, Census response, and Family unity) in Figures 16-21 respectively.

As shown, a gap opens in Stay Home between high and low social capital counties as the pandemic progresses. There are two key patterns. First, counties with greater community engagement — as measured by Community health and Association — experience smaller increases in social distancing (Stay Home) during the pandemic. Second, counties with greater individual commitment to social institutions - as measured by Community health, Institutional health, Associations, Voter turnout, and Census response - experience larger increases in social distancing. We now evaluate whether these patterns are statistically significant and robust to controlling for other country traits. 


\section{STATISTICAL ANALYSES}

\subsection{Regression specification}

To examine how the sensitivity of social distancing to COVID-19 cases and SDOs depends on social capital, we use the following regression specifications:

$$
\text { Stay Home }_{c t}=\alpha \text { Cases }_{c t}+\beta \text { Cases }_{c t} * \text { Social Capital }_{c}+\delta_{c}+\delta_{s t}+\varepsilon_{c t},
$$

and

$$
\text { Stay Home }_{c t}=\gamma \text { Restrictions }_{s t} * \text { Social Capital }_{c}+\delta_{c}+\delta_{s t}+\epsilon_{c t},
$$

where Social Capital is one of the eight county-level social capital measures defined above, $\delta_{c}$ and $\delta_{s t}$ denote county and state-day fixed effects, respectively, and $\varepsilon_{c t}$ and $\epsilon_{c t}$ are error terms. By including $\delta_{c}$, the analyses control for all time-invariant county traits, such as the level and distribution of income, population density, demographics, geographic location, etc. By including $\delta_{s t}$, the analyses control for all time-varying state characteristics, as well as all time-varying national and international factors. Since $\operatorname{Cases}_{c t}$ is measured at the county-day level, it can enter independently in equation (1). Since Restrictions $s_{s t}$ is measured at the state-day level, it is absorbed by $\delta_{s t}$ and does not enter independently in equation (2).

The estimates for $\beta$ and $\gamma$ provide information on whether the relationship between Stay Home and Cases and Restrictions respectively differs by the degree of social capital in the county. For example, if $\gamma>0$, this suggest that a state's SDOs have bigger effects on shelteringin-place in counties in the state with greater social capital. We examine both Cases and Restrictions because they each represent signals about the pandemic that might induce people to socially distance. In the regressions, there are about 300,000 county-day observations across 3,000 counties, depending on the specific variables used in the analyses. We report heteroskedasticity robust standard errors clustered at the county level. 


\subsection{Results}

We find conflicting results on the two composite social capital indicators, Social capital (US Congress) and Social capital (Penn State). As reported in Table 2, when examining Social capital (US Congress), the results suggest that the sensitivity of Stay Home to both Cases and Restrictions is greater in counties with more social capital. However, when examining Social capital (Penn State), the results suggest the opposite: the estimates indicate that social distancing is less responsive to Cases and Restrictions in counties with more social capital.

As discussed above, one possible explanation for these findings is that (1) the community engagement and individual commitment features have opposite effects on social distancing and (2) the two composite social capital indexes put different weights on these underlying features. In particular, when community engagement is stronger - and people spend more time with others through teams, clubs, organizations, and association, people in that community might be more reluctant to separate from those highly-valued connections and socially distance. Since the Community health and Associations indicators are designed to measure community engagement, this would suggest the counties with higher Community health and Associations values will socially distance less in response to Cases or Restrictions than otherwise similar counties. In turn, when individual commitment to broader social institutions is stronger-and people are more likely to vote, fill-out census forms, contribute to social institutions, people in that community might be more willing to incur the inconveniences of social distancing. This suggests that counties with higher Institutional health, Voter turnout, and Census response will socially distance more in response to the pandemic. This cost-benefit view of social capital and social distancing also yields predictions about Family unity. Specifically, given the especially pronounced challenges to single parents of coordinating work, childcare, and household obligations while sheltering-in-place and the comparatively high "loneliness" costs to single adults from sheltering-in-place, counties with higher Family unity will tend to value the net benefits from social distancing higher than in communities with more single parents or single adults. 
The results are consistent with this explanation. As shown in Tables 3 and 4, the sensitivity of Stay Home to both Cases and Restrictions is (1) weaker in counties with higher Community health and Associations and (2) stronger in counties with higher Institutional health, Voter turnout, Census response, and Family unity. When people in a county face comparatively high costs to disengaging from the community, e.g., when Community health and Associations are larger, social distancing is relatively less sensitive to the pandemic. In turn, the willingness and ability of people in a county to contribute to broad social goals and institutions - as proxied by Institutional health, Voter turnout, Census response, and Family unity - is positively associated with social distancing in response to new local COVID-19 cases and official social distancing restrictions. The estimated effects are considerable. For example, consider two otherwise similar counties in the same state, where the "high" county has Institutional heath at the $75^{\text {th }}$ percentile of the sample distribution and the "low" county has Institutional heath at the $25^{\text {th }}$ percentile, so that the difference in Institutional heath is 1.35 . Next "expose" these two counties to the same policy change, where the state increases Restrictions from 0 to 4 . The estimated coefficient in column (3) of Table 4 suggests that the increase in the percentage of mobile phones that do not leave home each day would be almost four percentage points greater in the high Institutional health county relative to the low one. For comparison purposes, about 28 percent of mobile devices stay at home on average day in the average county.

The results are also robust to controlling for other county factors that could shape the sensitivity of social distancing to Cases and Restrictions. For example, the sensitivity of social distancing to COVID-19 cases and official mobility restrictions could depend on the level of income in the county, the county's population density, the proportion of older people in the county, and the number of days since the county had its first confirmed COVID-19 case since these factors might shape the perceived costs and benefits from sheltering-in-place both in terms of health and economics. We were concerned that omitting the interaction between these country characteristics and Cases and Restrictions might yield biased estimates of $\beta$ and $\gamma$ when estimating equations (1) and (2). As shown in Tables (5) and (6), however, all of the results hold 
when including, respectively, the interaction between Cases and Restrictions and log(income per capita), Population density, and \%aged 65+, and Days since $1^{\text {st }}$ case. Including these additional interaction terms attenuates the estimated coefficients on $\beta$ and $\gamma$, but all of the parameters remain statistically significant and of the same sign.

\section{CONCLUSIONS}

Social capital helps account for the enormous cross-county differences in social distancing in response to the COVID-19 pandemic; but, it is essential to distinguish between the community engagement and individual commitment to societal institutions features of social capital to understand how county characteristics shape social distancing choices. The sensitivity of social distancing to COVID-19 cases and SDOs is weaker in counties with stronger community engagement and stronger in counties with stronger individual commitment to societal institutions. That is, when individuals in a community participate more intensively in community activities, they find it especially difficult to disengage from those activities and socially distance. In turn, when individuals in a community demonstrate their commitment to contributing to social goals, they find it easier to socially distance to contribute to public health. These two features of social capital work in opposite directions in shaping the degree to which communities socially distanced in response to the pandemic.

\section{REFERENCES}

Barrios, J.M., Benmelech, E., Hochberg, Y.V., Sapienza, P., Zingales, L., 2020. Civic capital and social distancing during the COVID-19 pandemic. NBER Working paper 27320.

Bourdieu, P. 1986. The forms of capital. In Handbook of Theory and Research for the Sociology of Education, ed. J. Richardson, pp. 241-258. Westport, CT: Greenwood.

Coleman, J.S., 1988. Social capital in the creation of human capital. American journal of sociology, 94, pp.S95-S120.

Fukuyama, F., 1995. Trust: The social virtues and the creation of prosperity (Vol. 99). New York: Free press.

Guiso, L., Sapienza, P., Zingales, L., 2011. Civic capital as the missing link. In Handbook of Social Economics, ed. J. Benhabib, A. Bisin, and M. Jackson, Vol1, pp. 417-480. Elsevier. 
House, J. S., Landis, K. R., \& Umberson, D. (1988). Social relationships and health. Science, 241(4865), 540-545.

Loury, G., 1977. A dynamic theory of racial income differences. In Women, minorities, and employment discrimination, ed. P.A. Wallace, A.M. La Mond, pp. 153-86. Lexington, MA: Heath.

Pretty, J., 2003. Social capital and the collective management of resources. Science, 302(5652), 1912-1914.

Putnam, R.D., 2000. Bowling alone: The collapse and revival of American community. New York, NY: Simon \& Schuster.

Rupasingha, A., Goetz, S. J., \& Freshwater, D. (2006, with updates). The production of social capital in US counties. Journal of Socio-Economics, 35, 83-10

Snyder-Mackler, N., Burger, J. R., Gaydosh, L., Belsky, D. W., Noppert, G. A., Campos, F. A., ... \& Harris, K. M. (2020). Social determinants of health and survival in humans and other animals. Science, 368(6493).

U.S. Congress. 2018. The geography of social capital in America. Joint Economic Committee: SCP Report No. 1-18. 


\section{Table 1 Summary Statistics}

This table presents the summary statistics. Our sample consists of data on 3,142 U.S. counties from Jan 22, 2020 to Apr 30, 2020.

\begin{tabular}{|c|c|c|c|c|c|c|c|c|}
\hline & $\mathrm{N}$ & Mean & Std. Dev. & $\mathrm{p} 10$ & $\mathrm{p} 25$ & $\mathrm{p} 50$ & $\mathrm{p} 75$ & p90 \\
\hline \multicolumn{9}{|l|}{ COVID-19 } \\
\hline Cases & 314,113 & 0.281 & 0.748 & 0 & 0 & 0 & 0.134 & 0.944 \\
\hline Restrictions & 314,113 & 1.630 & 1.962 & 0 & 0 & 0 & 4 & 5 \\
\hline Restrictions (state by day level) & 5,100 & 1.701 & 2.022 & 0 & 0 & 0 & 4 & 5 \\
\hline \multicolumn{9}{|l|}{ Mobility } \\
\hline Stay Home & 314,113 & 27.932 & 8.182 & 18.138 & 21.601 & 26.934 & 33.446 & 39.195 \\
\hline \multicolumn{9}{|l|}{ Social capital } \\
\hline Social capital (US congress) & 2,992 & 0 & 1 & -1.210 & -0.690 & -0.093 & 0.644 & 1.421 \\
\hline Social capital (PennState) & 3,139 & 0.001 & 1.260 & -1.202 & -0.756 & -0.226 & 0.478 & 1.583 \\
\hline Community health & 3,139 & 0 & 1 & -1.012 & -0.669 & -0.226 & 0.440 & 1.342 \\
\hline Associations (normalized) & 3,139 & 0.235 & 0.136 & 0.101 & 0.145 & 0.201 & 0.289 & 0.421 \\
\hline Institutional health & 3,112 & 0 & 1 & -1.216 & -0.665 & -0.017 & 0.684 & 1.332 \\
\hline Voter turnout & 3,139 & 0.668 & 0.091 & 0.557 & 0.610 & 0.668 & 0.723 & 0.783 \\
\hline Census response & 3,139 & 0.704 & 0.113 & 0.540 & 0.640 & 0.740 & 0.790 & 0.820 \\
\hline Family unity & 3,021 & 0 & 1 & -1.274 & -0.533 & 0.077 & 0.676 & 1.169 \\
\hline \multicolumn{9}{|l|}{ County Traits } \\
\hline log(income per capita) & 3,089 & 10.664 & 0.239 & 10.392 & 10.507 & 10.645 & 10.795 & 10.953 \\
\hline Population density & 3,142 & 267.647 & 1787.613 & 4.189 & 16.817 & 44.968 & 116.510 & 390.083 \\
\hline$\%$ aged $65+$ & 3,142 & 17.375 & 4.458 & 12.059 & 14.589 & 17.006 & 19.563 & 23.108 \\
\hline \#days since 1 st case & 314,113 & 6.305 & 11.643 & 0 & 0 & 0 & 8 & 26 \\
\hline
\end{tabular}




\section{Table 2 Social Distancing in Response to the Pandemic: Aggregate social capital indexes}

This table presents regression results of the relationship between social distancing and both new COVID-19 cases and official restrictions on mobility as functions of social capital. The dependent variable is Stay Home, which is the percentage of mobile devices in a county that do not leave home during the day. Cases is the natural logarithm of one plus the average number of daily new confirmed COVID-19 cases in the previous seven days in the county. Restrictions is the total number of restrictions on mobility in each country in each day, where these restrictions include stay-at-home orders, the closing of restaurants and bars, the closing of other non-essential businesses, limits on social gatherings, and the closing of schools. Social capital (US congress) is an overall index of social capital that aggregates information on (1) family unity, (2) community health, i.e., engagement in community activities, and (3) institutional health, i.e., commitment to society and trust in social institutions. Social capital (PennState) is an overall index of social capital that aggregates information on Associations, i.e., participation in community activities and non-profit organizations, and the degree to which people in a county turnout to vote (Voter turnout) and complete the census (Census report). The regressions include county and state-day fixed effects. The table reports t-statistics in parentheses, based on robust standard errors clustered at the county level. ***,**, * denote significance levels at 1\%, 5\% and 10\% respectively.

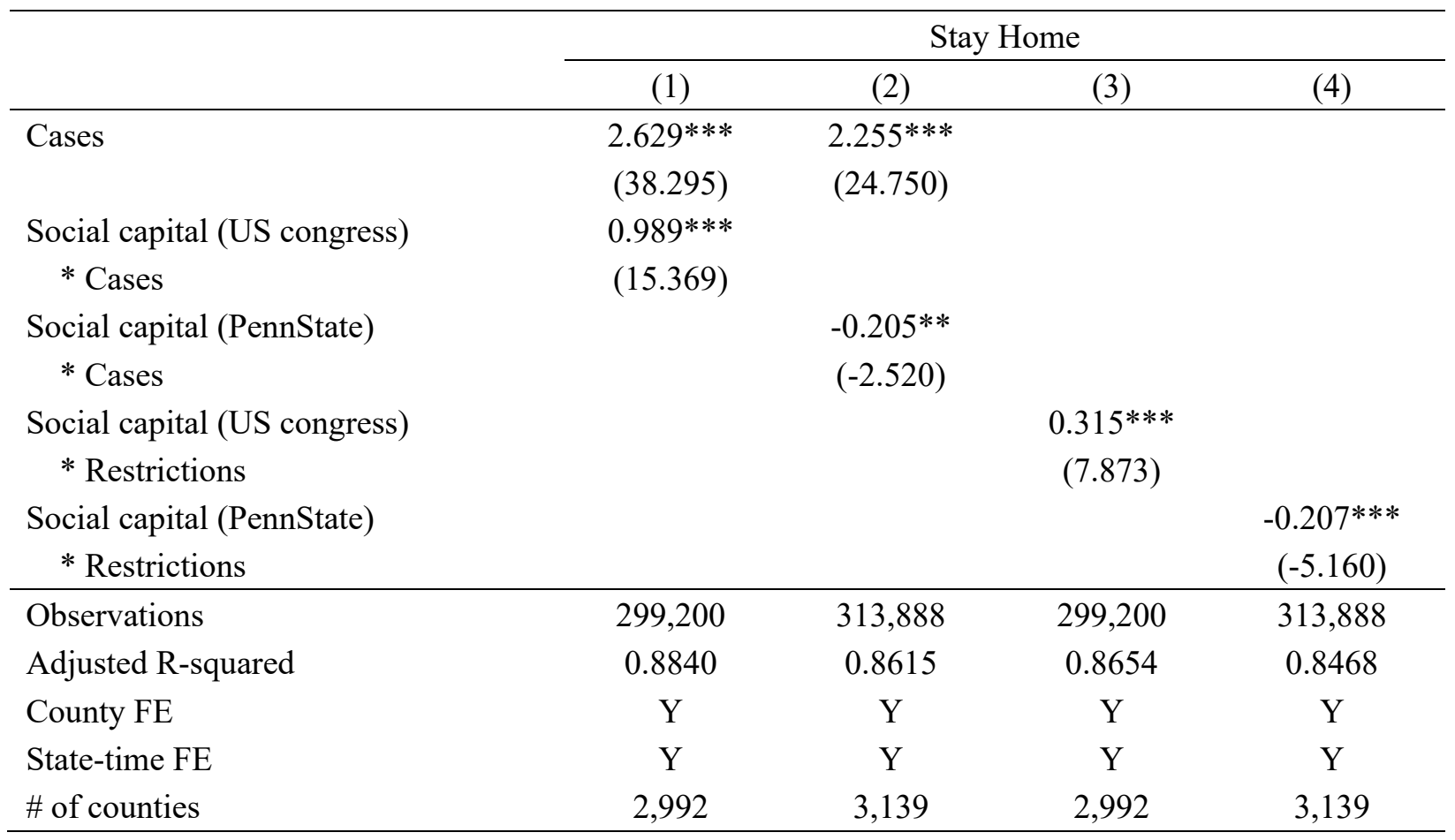




\section{Table 3 Social Distancing in Response to New Cases: Individual Social Capital Indicators}

This table presents regression results of the relationship between social distancing and new COVID-19 cases as functions of the individual social capital indicators. The dependent variable is Stay Home, which is the percentage of mobile devices in a county that do not leave home during the day. Cases is the natural logarithm of one plus the average number of daily new COVID-19 cases during the previous seven days in the county. The social capital indicators include (1) Community health, which measures the degree to which individuals engage in community activities, (2) Associations (normalized), which is an index of the combined number of establishments related to community activities and non-profit organizations per 1,000 people, (3) Institutional health, which measures commit to society and trust in institutions, (4) Voter turnout, which is the percentage of people who voted in the 2012 Presidential election relative to eligible voters, (5) Census response, which is the proportion of households that responded to the 2010 Census, and (6) Family unity, which measures family structure and stability within a county. The regressions include county and state-day fixed effects. The table reports t-statistics in parentheses based on robust standard errors clustered at the county level. ***, $* *, *$ denote significance levels at $1 \%, 5 \%$ and $10 \%$ respectively.

\begin{tabular}{|c|c|c|c|c|c|c|}
\hline & & & Sta & me & & \\
\hline & (1) & $(2)$ & (3) & (4) & $(5)$ & $(6)$ \\
\hline Cases & & $3.014 * * *$ & & & & \\
\hline & $(20.066)$ & $(22.546)$ & $(33.009)$ & $(-2.830)$ & $(-5.063)$ & $(38.858)$ \\
\hline Community health $*$ Cases & $-0.576 * * *$ & & & & & \\
\hline & $(-5.496)$ & & & & & \\
\hline Associations (normalized) $*$ Cases & & $-3.781 * * *$ & & & & \\
\hline & & $(-5.722)$ & & & & \\
\hline Institutional health $*$ Cases & & & $0.749 * * *$ & & & \\
\hline & & & $(10.571)$ & & & \\
\hline Voter turnout $*$ Cases & & & & $6.199 * * *$ & & \\
\hline & & & & $(6.611)$ & & \\
\hline Census response $*$ Cases & & & & & $7.117 * * *$ & \\
\hline & & & & & $(9.319)$ & \\
\hline Family unity $*$ Cases & & & & & & $0.922 * * *$ \\
\hline & & & & & & $(19.627)$ \\
\hline Observations & 313,888 & 313,888 & 311,188 & 313,888 & 313,888 & 302,100 \\
\hline Adjusted R-squared & 0.8619 & 0.8619 & 0.8669 & 0.8623 & 0.8626 & 0.8809 \\
\hline County FE & $\mathrm{Y}$ & $\mathrm{Y}$ & $\mathrm{Y}$ & $\mathrm{Y}$ & $\mathrm{Y}$ & $\mathrm{Y}$ \\
\hline State-time FE & $\mathrm{Y}$ & $\mathrm{Y}$ & $\mathrm{Y}$ & $\mathrm{Y}$ & $\mathrm{Y}$ & $\mathrm{Y}$ \\
\hline \# of counties & 3,139 & 3,139 & 3,112 & 3,139 & 3,139 & 3,021 \\
\hline
\end{tabular}




\section{Table 4 Social Distancing in Response to Restrictions on Mobility: Individual Social Capital Indicators}

This table presents regression results of the relationship between social distancing and official restrictions on mobility as functions of the individual social capital indicators. The dependent variable is Stay Home, which is the percentage of mobile devices in a county that do not leave home during the day. Restrictions is the total number of restrictions on mobility in each country in each day, where these restrictions include stay-at-home orders, the closing of restaurants and bars, the closing of other non-essential businesses, limits on social gatherings, and the closing of schools. The social capital indicators include (1) Community health, which measures the degree to which individuals engage in community activities, (2) Associations (normalized), which is an index of the combined number of establishments related to community activities and non-profit organizations per 1,000 people, (3) Institutional health, which measures commit to society and trust in institutions, (4) Voter turnout, which is the percentage of people who voted in the 2012 Presidential election relative to eligible voters, (5) Census response, which is the proportion of households that responded to the 2010 Census, and (6) Family unity, which measures family structure and stability within a county. The regressions include county and state-day fixed effects. The table reports t-statistics in parentheses based on robust standard errors clustered at the county level. *** $* *, *$ denote significance levels at $1 \%, 5 \%$ and $10 \%$ respectively.

\begin{tabular}{|c|c|c|c|c|c|c|}
\hline & & & Stay & & & \\
\hline & $(1)$ & $(2)$ & $(3)$ & (4) & $(5)$ & $(6)$ \\
\hline Community health $*$ Restrictions & $\begin{array}{c}-0.574 * * * \\
(-11.453)\end{array}$ & & & & & \\
\hline Associations (normalized) $*$ Restrictions & & $\begin{array}{c}-2.627 * * * \\
(-10.654)\end{array}$ & & & & \\
\hline Institutional health $*$ Restrictions & & & $\begin{array}{c}0.727 * * * \\
(17.381)\end{array}$ & & & \\
\hline Voter turnout $*$ Restrictions & & & & $\begin{array}{c}3.096 * * * \\
(7.655)\end{array}$ & & \\
\hline Census response $*$ Restrictions & & & & & $\begin{array}{c}3.729 * * * \\
(16.358)\end{array}$ & \\
\hline Family unity $*$ Restrictions & & & & & & $\begin{array}{c}0.340 * * * \\
(14.689)\end{array}$ \\
\hline Observations & 313,888 & 313,888 & 311,188 & 313,888 & 313,888 & 302,100 \\
\hline Adjusted R-squared & 0.8526 & 0.8484 & 0.8560 & 0.8462 & 0.8511 & 0.8642 \\
\hline County FE & Y & Y & $\mathrm{Y}$ & Y & $\mathrm{Y}$ & $\mathrm{Y}$ \\
\hline State-time FE & Y & $\mathrm{Y}$ & $\mathrm{Y}$ & $\mathrm{Y}$ & $\mathrm{Y}$ & $\mathrm{Y}$ \\
\hline \# of counties & 3,139 & 3,139 & 3,112 & 3,139 & 3,139 & 3,021 \\
\hline
\end{tabular}


Table 5 Social Distancing in Response to New Cases: Individual Social Capital Indicators, Robustness

This table presents regression results of the relationship between social distancing and official restrictions on mobility as functions of the individual social capital indicators, while controlling for additional county traits. Besides the variables defined above, the regression includes the interaction between Cases and the natural logarithm of income per capita (log(income per capita)), Population density, population per square mile, \%aged 65+, percentage of the population over 65 years old, \#days since 1st case, number of days since the county's first COVID-19 case. The regressions include county and state-day fixed effects. The table reports tstatistics in parentheses based on robust standard errors clustered at the county level. ${ }^{* * *},{ }^{* *},{ }^{*}$ denote significance levels at $1 \%, 5 \%$ and $10 \%$ respectively.

\begin{tabular}{|c|c|c|c|c|c|c|}
\hline & \multicolumn{6}{|c|}{ Stay Home } \\
\hline & $(1)$ & $(2)$ & $(3)$ & $(4)$ & $(5)$ & $(6)$ \\
\hline Cases & $\begin{array}{c}-31.544 * * * \\
(-11.308)\end{array}$ & $\begin{array}{c}-32.018^{* * *} \\
(-11.388)\end{array}$ & $\begin{array}{c}-24.700 * * * \\
(-8.862)\end{array}$ & $\begin{array}{c}-27.808 * * * \\
(-10.777)\end{array}$ & $\begin{array}{c}-29.544 * * * \\
(-12.280)\end{array}$ & $\begin{array}{r}-15.477 * * * \\
(-6.071)\end{array}$ \\
\hline Community health $*$ Cases & $\begin{array}{c}-0.741 * * * \\
(-7.372)\end{array}$ & & & & & \\
\hline Associations (normalized) $*$ Cases & & $\begin{array}{c}-5.880 * * * \\
(-8.169)\end{array}$ & & & & \\
\hline Institutional health $*$ Cases & & & $\begin{array}{c}0.338 * * * \\
(4.354)\end{array}$ & & & \\
\hline Voter turnout $*$ Cases & & & & $\begin{array}{c}2.499 * * * \\
(2.621)\end{array}$ & & \\
\hline Census response $*$ Cases & & & & & $\begin{array}{c}4.786^{* * *} \\
(8.147)\end{array}$ & \\
\hline Family unity $*$ Cases & & & & & & $\begin{array}{c}0.660 * * * \\
(13.896)\end{array}$ \\
\hline $\log ($ income per capita $) *$ Cases & $\begin{array}{c}3.269 * * * \\
(12.653)\end{array}$ & $\begin{array}{c}3.436 * * * \\
(13.030)\end{array}$ & $\begin{array}{c}2.679 * * * \\
(10.336)\end{array}$ & $\begin{array}{c}2.828 * * * \\
(11.034)\end{array}$ & $\begin{array}{c}2.805^{* * *} \\
(12.309)\end{array}$ & $\begin{array}{c}1.819 * * * \\
(7.760)\end{array}$ \\
\hline Population density $*$ Cases & $\begin{array}{c}-0.000 * * * \\
(-10.107)\end{array}$ & $\begin{array}{c}-0.000 * * * \\
(-8.957)\end{array}$ & $\begin{array}{c}-0.000 * * * \\
(-10.150)\end{array}$ & $\begin{array}{c}-0.000 * * * \\
(-9.707)\end{array}$ & $\begin{array}{c}-0.000 * * * \\
(-13.256)\end{array}$ & $\begin{array}{c}-0.000 * * * \\
(-8.530)\end{array}$ \\
\hline$\%$ aged $65+*$ Cases & $\begin{array}{c}-0.085 * * * \\
(-6.931)\end{array}$ & $\begin{array}{c}-0.076^{* * *} \\
(-6.328)\end{array}$ & $\begin{array}{c}-0.093 * * * \\
(-7.437)\end{array}$ & $\begin{array}{c}-0.102 * * * \\
(-7.724)\end{array}$ & $\begin{array}{c}-0.098 * * * \\
(-7.848)\end{array}$ & $\begin{array}{c}-0.089 * * * \\
(-7.428)\end{array}$ \\
\hline \#days since 1 st case $*$ Cases & $\begin{array}{c}-0.026 * * * \\
(-12.836)\end{array}$ & $\begin{array}{c}-0.027 * * * \\
(-13.226)\end{array}$ & $\begin{array}{c}-0.021 * * * \\
(-9.615)\end{array}$ & $\begin{array}{c}-0.024 * * * \\
(-11.350)\end{array}$ & $\begin{array}{c}-0.023 * * * \\
(-11.038) \\
\end{array}$ & $\begin{array}{c}-0.018 * * * \\
(-9.513)\end{array}$ \\
\hline Observations & 308,688 & 308,688 & 305,988 & 308,688 & 308,688 & 297,000 \\
\hline Adjusted R-squared & 0.8659 & 0.8660 & 0.8694 & 0.8654 & 0.8658 & 0.8824 \\
\hline County FE & $\mathrm{Y}$ & $\mathrm{Y}$ & $\mathrm{Y}$ & $\mathrm{Y}$ & $\mathrm{Y}$ & $\mathrm{Y}$ \\
\hline State-time FE & $\mathrm{Y}$ & $\mathrm{Y}$ & $\mathrm{Y}$ & Y & $\mathrm{Y}$ & $\mathrm{Y}$ \\
\hline \# of counties & 3,087 & 3,087 & 3,060 & 3,087 & 3,087 & 2,970 \\
\hline
\end{tabular}


Table 6 Social Distancing in Response to Restrictions on Mobility: Individual Social Capital Indicators, Robustness

This table presents regression results of the relationship between social distancing and official mobility restrictions as functions of the social capital indicators, while controlling for additional county traits. Besides the variables defined above, the regression includes the interaction between Restrictions and the natural logarithm of income per capita (log(income per capita)), Population density, population per square mile, \%aged 65+, percentage of the population over 65 years old, \#days since 1st case, number of days since the county's first COVID-19 case. The regressions include county and state-day fixed effects. The table reports tstatistics in parentheses based on robust standard errors clustered at the county level. $*^{* *}, * *, *$ denote significance levels at $1 \%, 5 \%$ and $10 \%$ respectively.

\begin{tabular}{|c|c|c|c|c|c|c|}
\hline & \multicolumn{6}{|c|}{ Stay Home } \\
\hline & $(1)$ & $(2)$ & (3) & $(4)$ & $(5)$ & $(6)$ \\
\hline Community health $*$ Restrictions & $\begin{array}{c}-0.421 * * * \\
(-7.176)\end{array}$ & & & & & \\
\hline Associations (normalized) * Restrictions & & $\begin{array}{c}-2.284 * * * \\
(-8.488)\end{array}$ & & & & \\
\hline Institutional health $*$ Restrictions & & & $\begin{array}{c}0.352 * * * \\
(8.854)\end{array}$ & & & \\
\hline Voter turnout $*$ Restrictions & & & & $\begin{array}{c}1.780 * * * \\
(4.718)\end{array}$ & & \\
\hline Census response $*$ Restrictions & & & & & $\begin{array}{c}1.299 * * * \\
(6.201)\end{array}$ & \\
\hline Family unity $*$ Restrictions & & & & & & $\begin{array}{c}0.171 * * * \\
(9.218)\end{array}$ \\
\hline $\log ($ income per capita $) *$ Restrictions & $\begin{array}{c}2.248 * * * \\
(18.492)\end{array}$ & $\begin{array}{c}2.340 * * * \\
(18.191)\end{array}$ & $\begin{array}{c}1.447 * * * \\
(11.032)\end{array}$ & $\begin{array}{c}1.814 * * * \\
(13.676)\end{array}$ & $\begin{array}{c}1.894 * * * \\
(14.997)\end{array}$ & $\begin{array}{c}1.833 * * * \\
(14.429)\end{array}$ \\
\hline Population density * Restrictions & $\begin{array}{c}0.000 \\
(0.674)\end{array}$ & $\begin{array}{c}0.000 \\
(0.641)\end{array}$ & $\begin{array}{c}0.000 \\
(0.991)\end{array}$ & $\begin{array}{c}0.000 \\
(0.817)\end{array}$ & $\begin{array}{c}0.000 \\
(0.779)\end{array}$ & $\begin{array}{c}0.000 \\
(0.818)\end{array}$ \\
\hline$\%$ aged $65+*$ Restrictions & $\begin{array}{c}-0.035 * * * \\
(-6.215)\end{array}$ & $\begin{array}{c}-0.041 * * * \\
(-8.503)\end{array}$ & $\begin{array}{c}-0.071 * * * \\
(-13.878)\end{array}$ & $\begin{array}{c}-0.071 * * * \\
(-14.345)\end{array}$ & $\begin{array}{c}-0.058 * * * \\
(-11.307)\end{array}$ & $\begin{array}{c}-0.065 * * * \\
(-13.151)\end{array}$ \\
\hline \#days since 1 st case $*$ Restrictions & $\begin{array}{c}0.012^{* * *} \\
(6.232)\end{array}$ & $\begin{array}{c}0.016^{* * *} \\
(7.757)\end{array}$ & $\begin{array}{c}0.018^{* * *} \\
(9.557)\end{array}$ & $\begin{array}{c}0.019 * * * \\
(9.782)\end{array}$ & $\begin{array}{c}0.018^{* * * *} \\
(9.283)\end{array}$ & $\begin{array}{c}0.020 * * * \\
(10.393)\end{array}$ \\
\hline Observations & 308,688 & 308,688 & 305,988 & 308,688 & 308,688 & 297,000 \\
\hline Adjusted R-squared & 0.8693 & 0.8685 & 0.8715 & 0.8671 & 0.8673 & 0.8838 \\
\hline County FE & $\mathrm{Y}$ & Y & $\mathrm{Y}$ & Y & Y & Y \\
\hline State-time FE & $\mathrm{Y}$ & $\mathrm{Y}$ & $\mathrm{Y}$ & $\mathrm{Y}$ & $\mathrm{Y}$ & $\mathrm{Y}$ \\
\hline \# of counties & 3,087 & 3,087 & 3,060 & 3,087 & 3,087 & 2,970 \\
\hline
\end{tabular}




\section{Appendix Table 1 Variable definition}

This table shows the definition of variables used in our analyses and the corresponding sources of those data.

\begin{tabular}{|c|c|c|}
\hline Variable & Description & Source \\
\hline \multicolumn{3}{|l|}{ COVID-19 } \\
\hline Cases & $\begin{array}{l}\text { The natural logarithm of one plus the average number of daily new confirmed } \\
\text { COVID-19 cases in the past } 7 \text { days in that county. }\end{array}$ & \multirow{2}{*}{$\begin{array}{l}\text { Center for Systems Science } \\
\text { and Engineering at Johns } \\
\text { Hopkins University }\end{array}$} \\
\hline $\begin{array}{l}\text { \#days since } 1 \text { st } \\
\text { case }\end{array}$ & $\begin{array}{l}\text { The number of days passed since the day of first confirmed COVID-19 case of a } \\
\text { county. }\end{array}$ & \\
\hline Restrictions & The total number of lockdown policies in place for each day in each county. & Fullman et. al (2020) \\
\hline \multicolumn{3}{|l|}{ Mobility } \\
\hline Stay Home & $\begin{array}{l}\text { The percentage of the number of devices that do not leave their home throughout the } \\
\text { day completely (stay-at-home devices) to the total number of devices in that county. }\end{array}$ & SafeGraph \\
\hline \multicolumn{3}{|l|}{ Social Capital } \\
\hline $\begin{array}{l}\text { Social capital } \\
\text { (US congress) }\end{array}$ & $\begin{array}{l}\text { An overall index captures family structure and stability, community cohesion, and } \\
\text { trust and confidence in institutions of each county. }\end{array}$ & \multirow{4}{*}{$\begin{array}{l}\text { Joint Economic Committee } \\
\text { of U.S. Congress }\end{array}$} \\
\hline Family unity & $\begin{array}{l}\text { An index measures family structure and stability of a county, with subcomponents } \\
\text { of 1) share of births in past year to women who were unmarried, 2) share of women } \\
\text { ages 35-44 who are currently married and not separated, and 3) share of own children } \\
\text { living in a single-parent family. }\end{array}$ & \\
\hline $\begin{array}{l}\text { Community } \\
\text { health }\end{array}$ & $\begin{array}{l}\text { An index measures community cohesion, with subcomponents of 1) the number of } \\
\text { non-religious non-profits organizations, 2) religious congregations, and 3) degree of } \\
\text { involvement in informal social activities such as attending public meeting, helping } \\
\text { neighbors, and taking part in political affairs. }\end{array}$ & \\
\hline $\begin{array}{l}\text { Institutional } \\
\text { health }\end{array}$ & $\begin{array}{l}\text { An index measures trust and confidence in institutions, with subcomponents of 1) } \\
\text { voting rate in } 2012 \text { and } 2016 \text { presidential elections, 2) response rate for } 2010 \text { census, } \\
\text { and } 3 \text { ) confidence in institutions. }\end{array}$ & \\
\hline $\begin{array}{l}\text { Social capital } \\
\text { (PennState) }\end{array}$ & $\begin{array}{l}\text { An overall index captures the number of establishments related community } \\
\text { activities, the participation rate in the presidential election, the response rate to the } \\
\text { Census Bureau's decennial census, and the number of non-profit organizations of } \\
\text { each county. }\end{array}$ & $\begin{array}{l}\text { Northeast Regional Center } \\
\text { for Rural Development of } \\
\text { Penn State University }\end{array}$ \\
\hline
\end{tabular}




\begin{tabular}{|c|c|c|}
\hline $\begin{array}{l}\text { Associations } \\
\text { (normalized) }\end{array}$ & $\begin{array}{l}\text { The average of (a) the min-max scaling of the number of establishments related to community } \\
\text { activities per } 1,000 \text { people and (b) the min-max scaling of non-profit organizations (excluding } \\
\text { those with an international focus) per } 1,000 \text { population, where the min-max scaling of a variable } \\
\mathrm{X} \text { is }\left(X-X_{\min }\right) /\left(X_{\max }-X_{\min }\right) \text {. }\end{array}$ & \\
\hline Voter turnout & $\begin{array}{l}\text { Number of people who voted in the } 2012 \text { presidential election relative to the number of eligible } \\
\text { voters in the county. }\end{array}$ & \\
\hline $\begin{array}{l}\text { Census } \\
\text { response }\end{array}$ & The response rate to the Census Bureau's 2010 census. & \\
\hline \multicolumn{3}{|l|}{ County Traits } \\
\hline $\begin{array}{l}\log (\text { income per } \\
\text { capita) }\end{array}$ & The natural logarithm of personal income per capita in 2018 & $\begin{array}{l}\text { U.S. Bureau of } \\
\text { Economic } \\
\text { Analysis }\end{array}$ \\
\hline $\begin{array}{l}\text { Population } \\
\text { density }\end{array}$ & The population per square mile of land area in 2016 & \multirow{2}{*}{$\begin{array}{l}\text { American } \\
\text { Community } \\
\text { Survey }\end{array}$} \\
\hline$\%$ aged $65+$ & The percentage of the population with an age over 65 years old in 2016 & \\
\hline
\end{tabular}




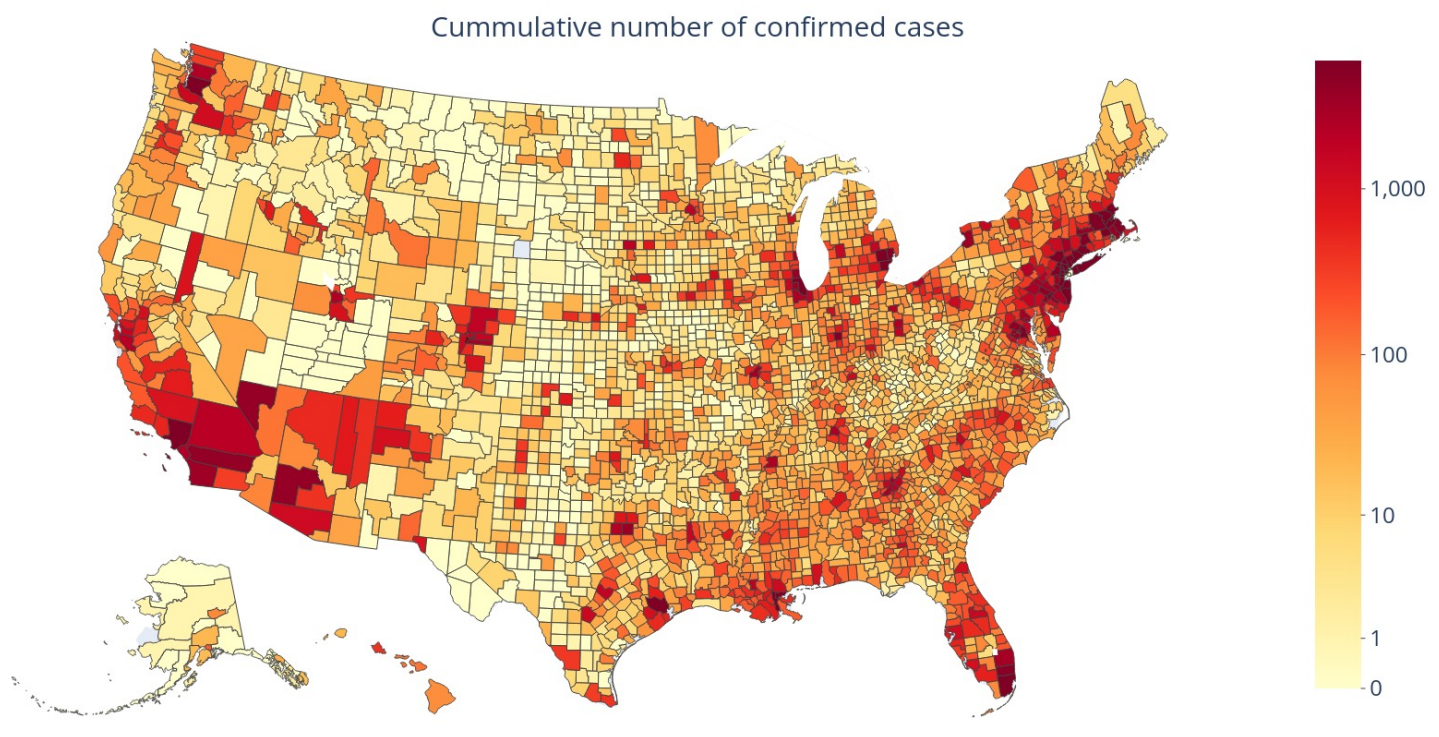

\section{Figure 1. Cumulative number of confirmed cases.}

This figure shows the cummulative number of confirmed cases of each U.S. county as of Apr 30, 2020. The darker color means more confirmed cases.

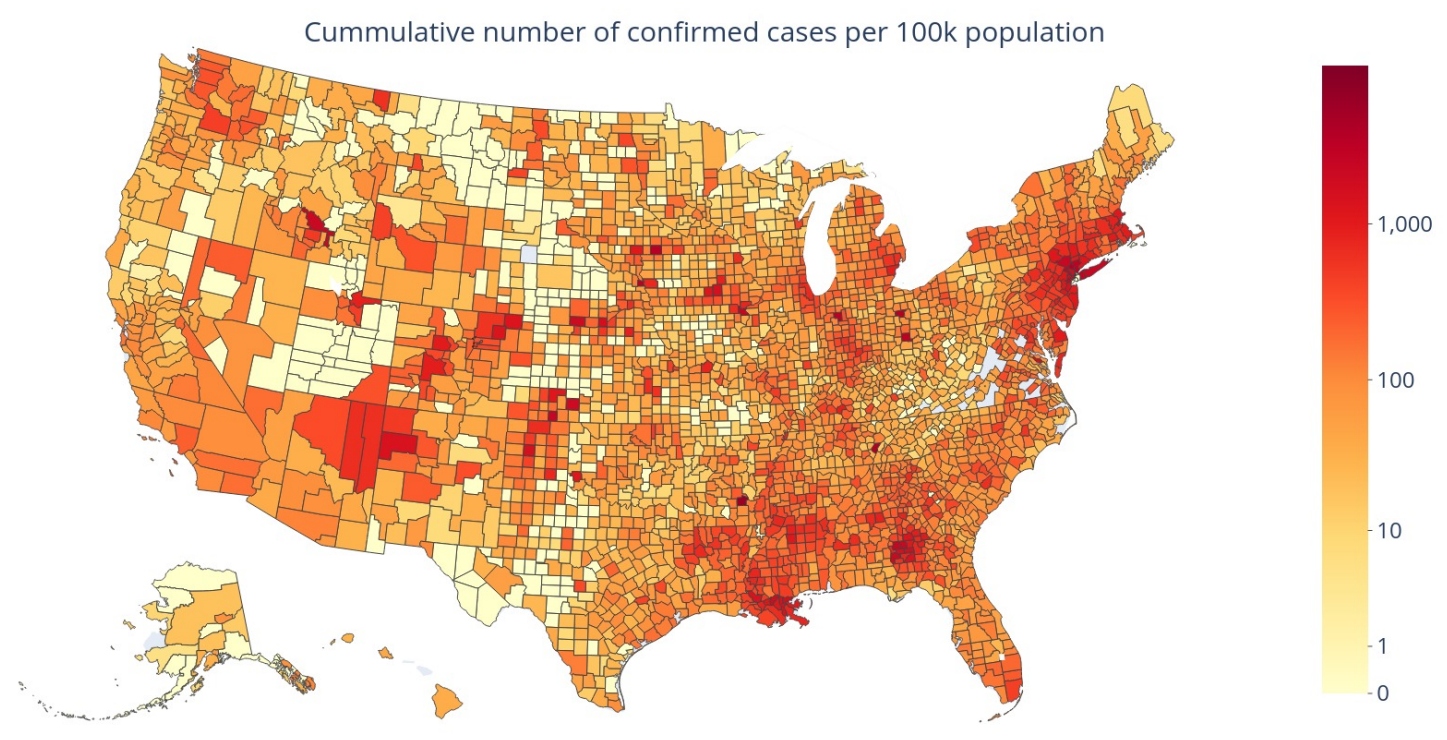

Figure 2. Cumulative number of confirmed cases per 100,000 population.

This figure shows the cummulative number of confirmed cases per 100,000 population of each U.S. county as of Apr 30, 2020. The darker color means more confirmed cases per 100,000 population. 


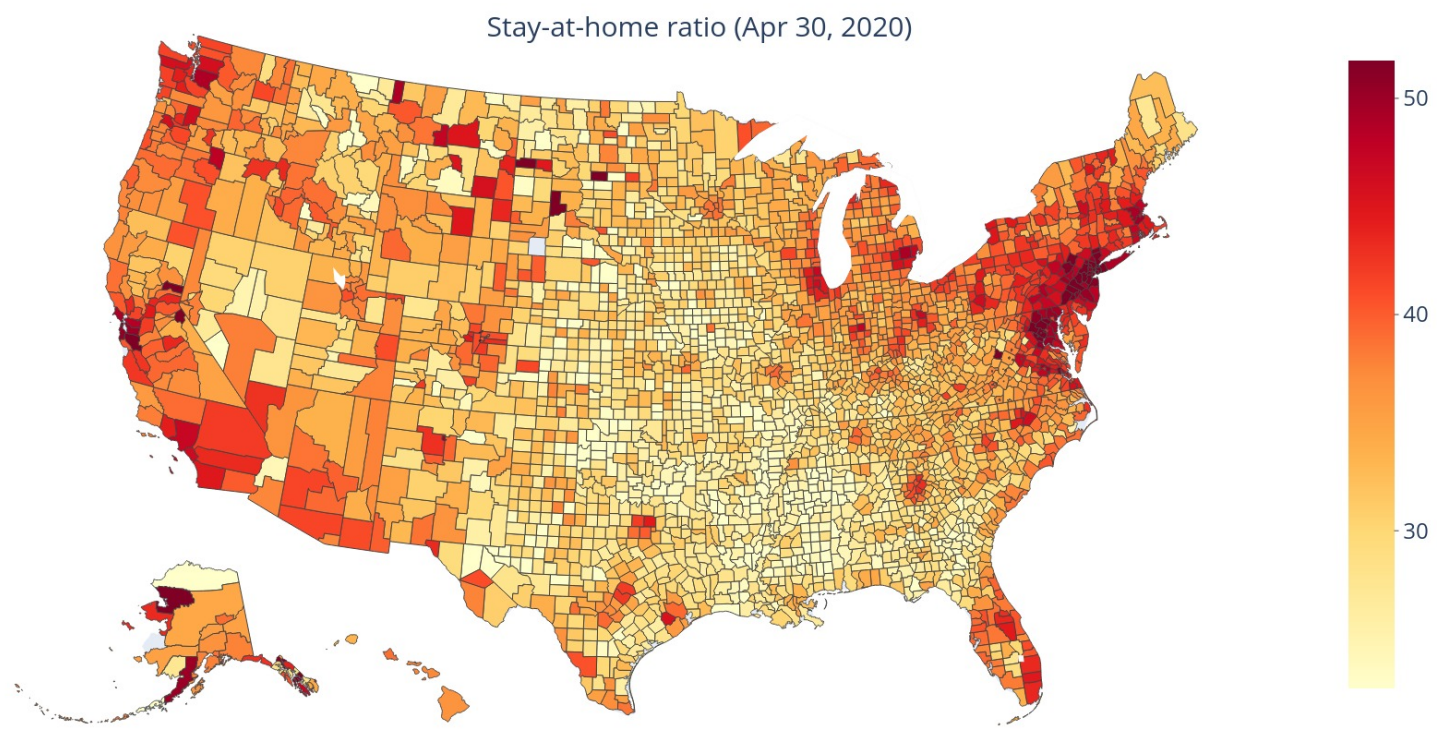

\section{Figure 3. Stay Home.}

This figure shows the stay-at-home ratio of each U.S. county on Apr 30, 2020, which is the last day of our sample period. The stay-at-home ratio is the number of devices not leaving home completely to the total number of devices. The darker color means higher stay-at-home ratio.

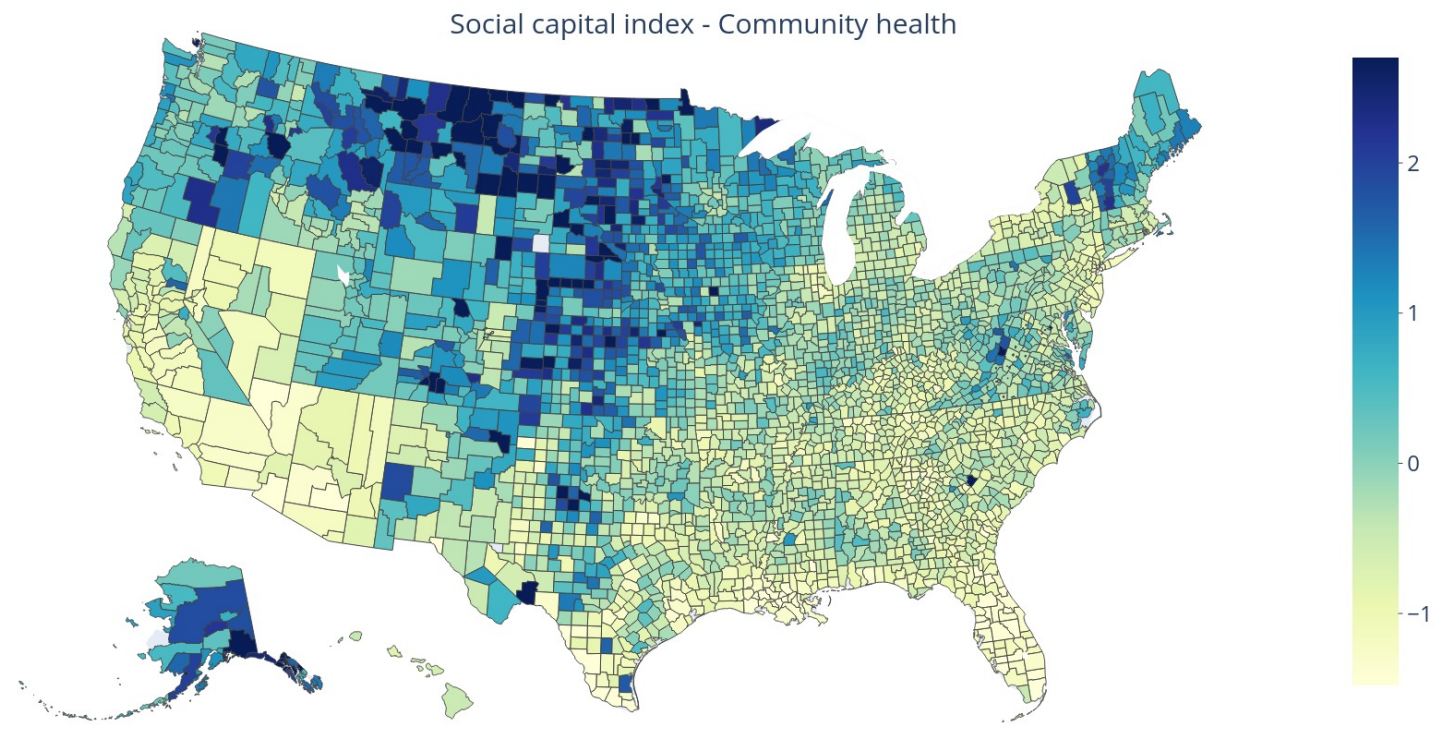

Figure 4. Community health.

This figure shows the Community health index of each U.S. county. Darker colors signify higher Community health. 


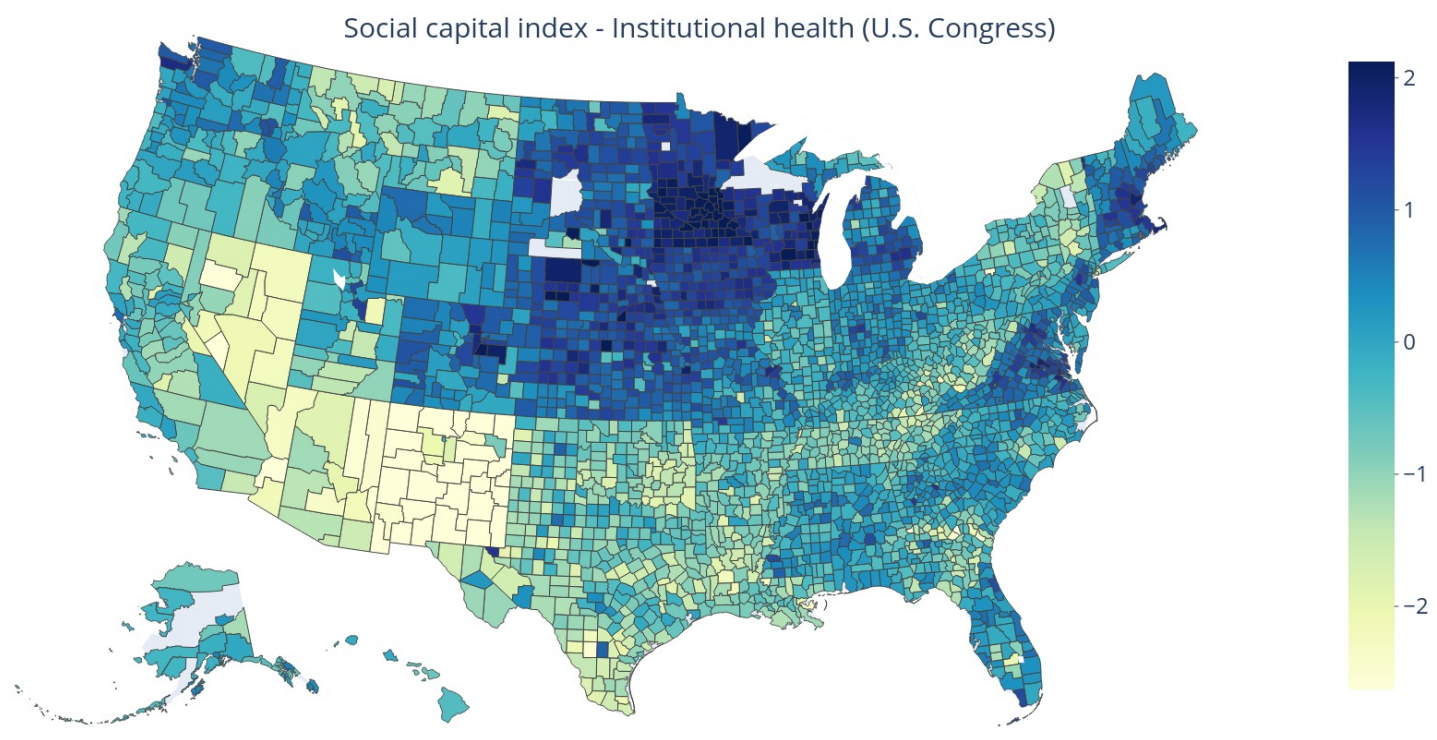

\section{Figure 5. Institutional health.}

This figure shows the Institutional health index of each U.S. county. Darker colors signify higher Institutional health.

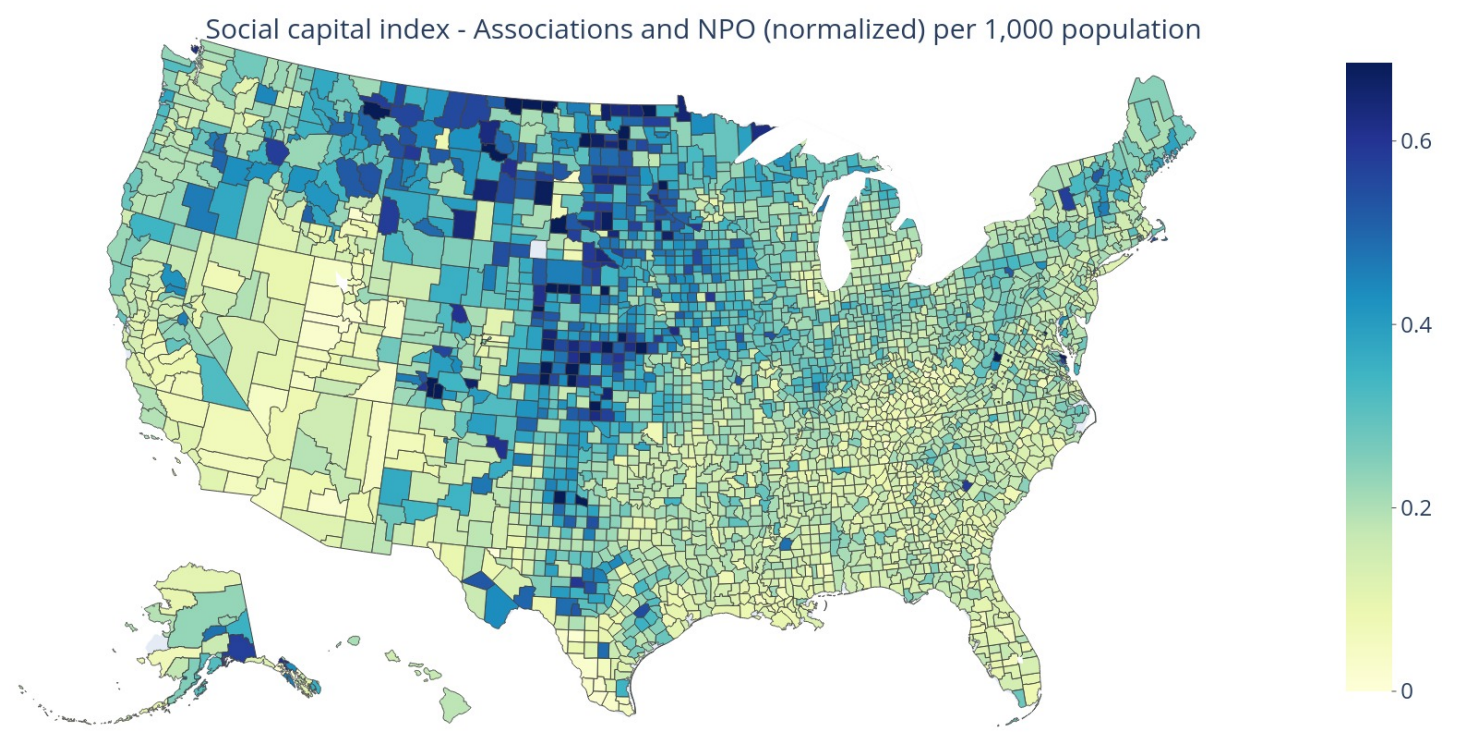

\section{Figure 6. Associations and NPOs.}

This figure shows the number of associations and NPOs per 1,000 population of each U.S. county. We normalize the number of associations per 1,000 population and the number of NPOs per 1,000 population to the range of 0 to 1 , and then take the average to calculate this index. Darker colors signify more associations and NPOs per 1,000 population. 


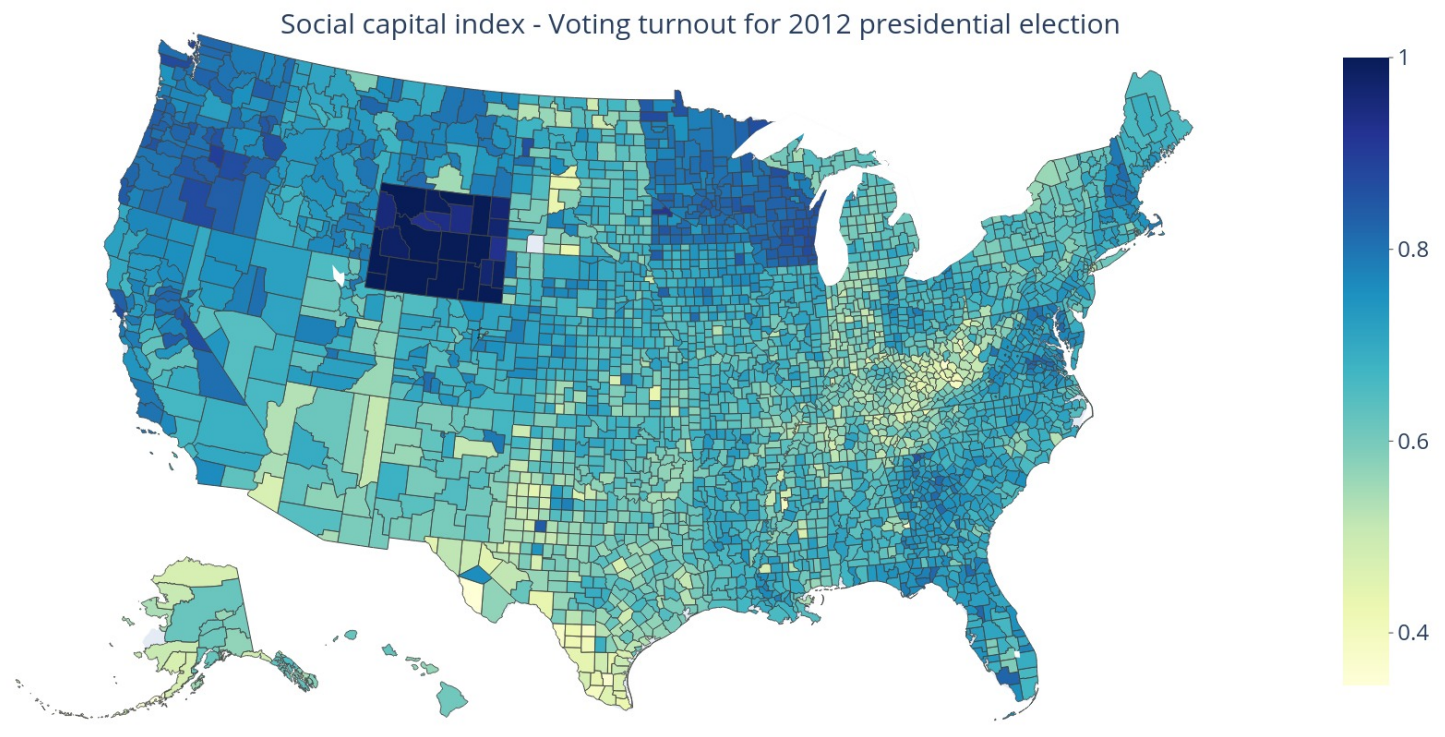

\section{Figure 7. Voter turnout.}

This figure shows the voter turnout for 2012 presidential election of each U.S. county. Darker colors signify higher voter turnout.

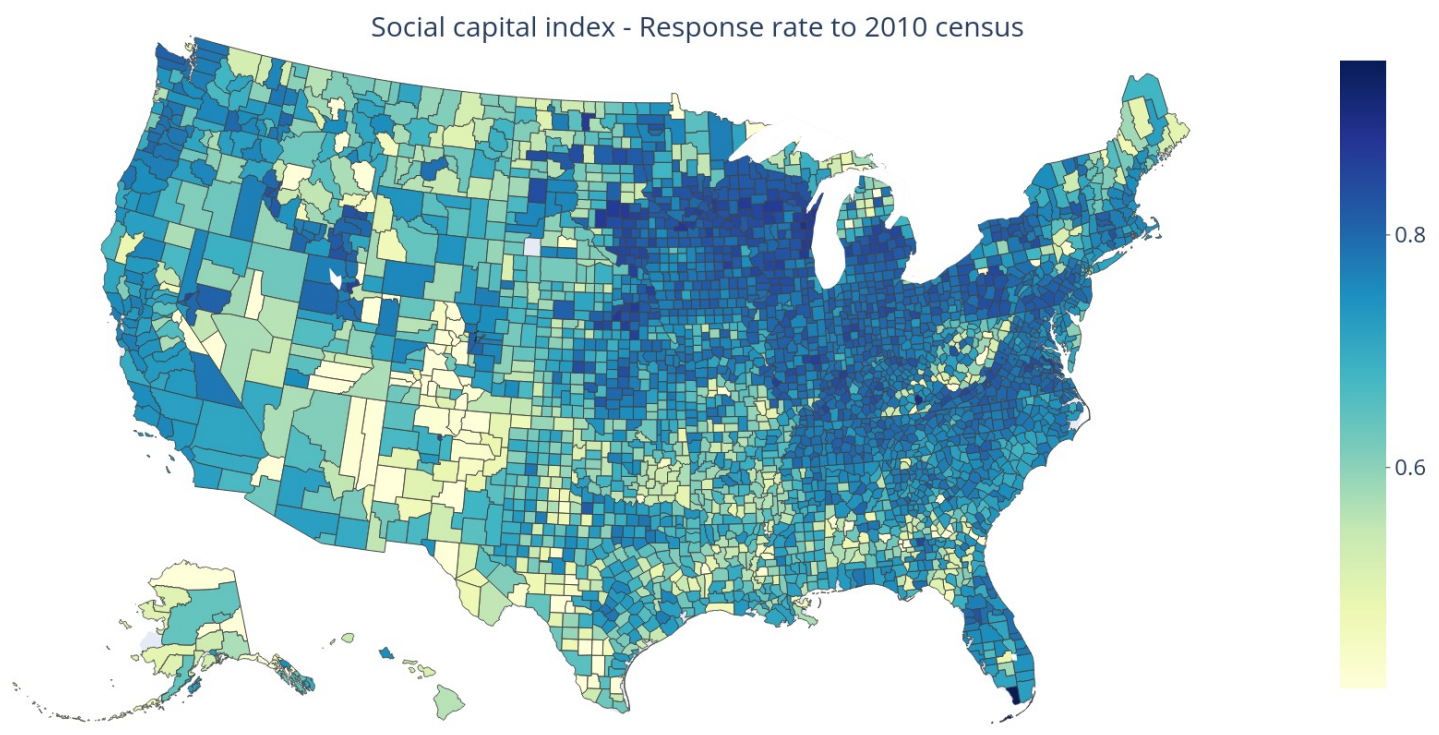

\section{Figure 7. Census response.}

This figure shows the response rate to the 2010 census of each U.S. county. Darker colors signify larger response rate. 


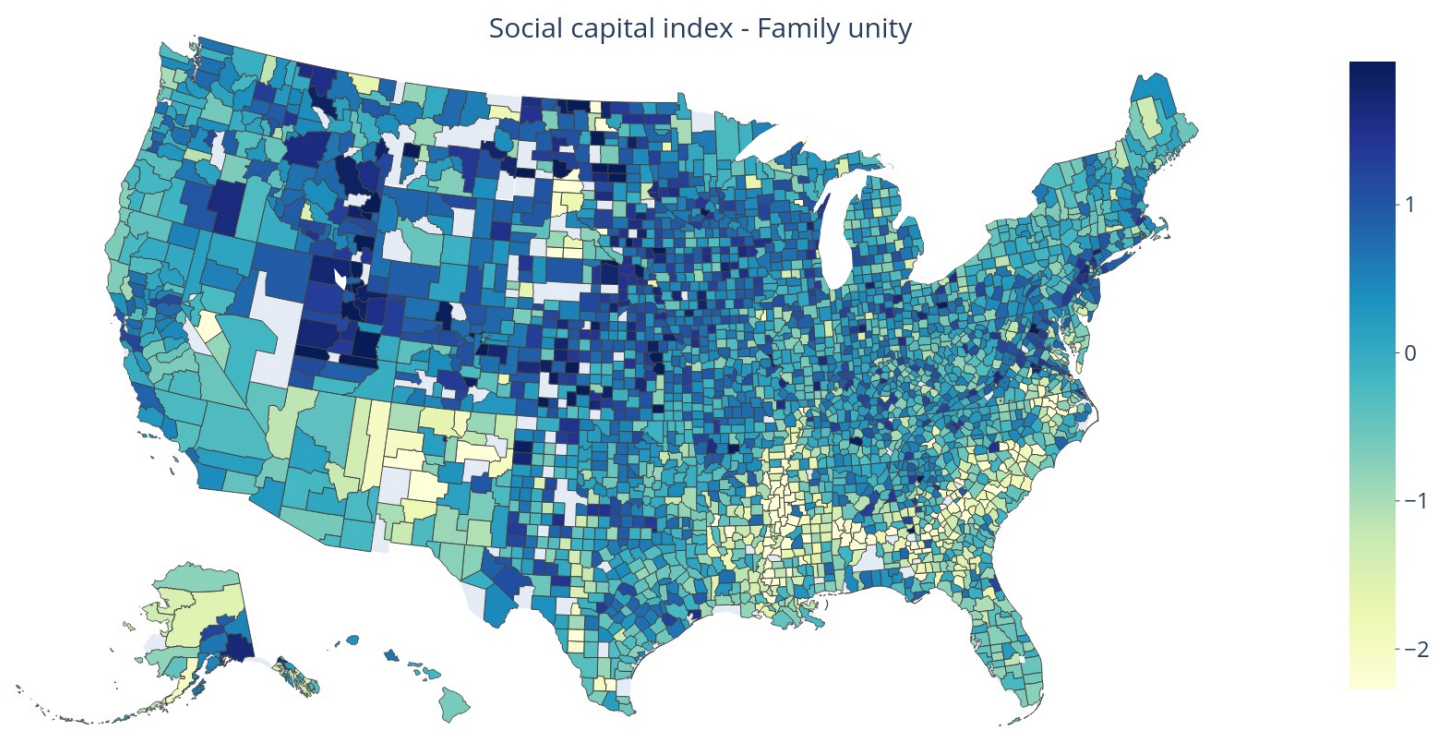

Figure 4. Family unity.

This figure shows the Family unity index of each U.S. county. Darker colors signify higher Family unity. 


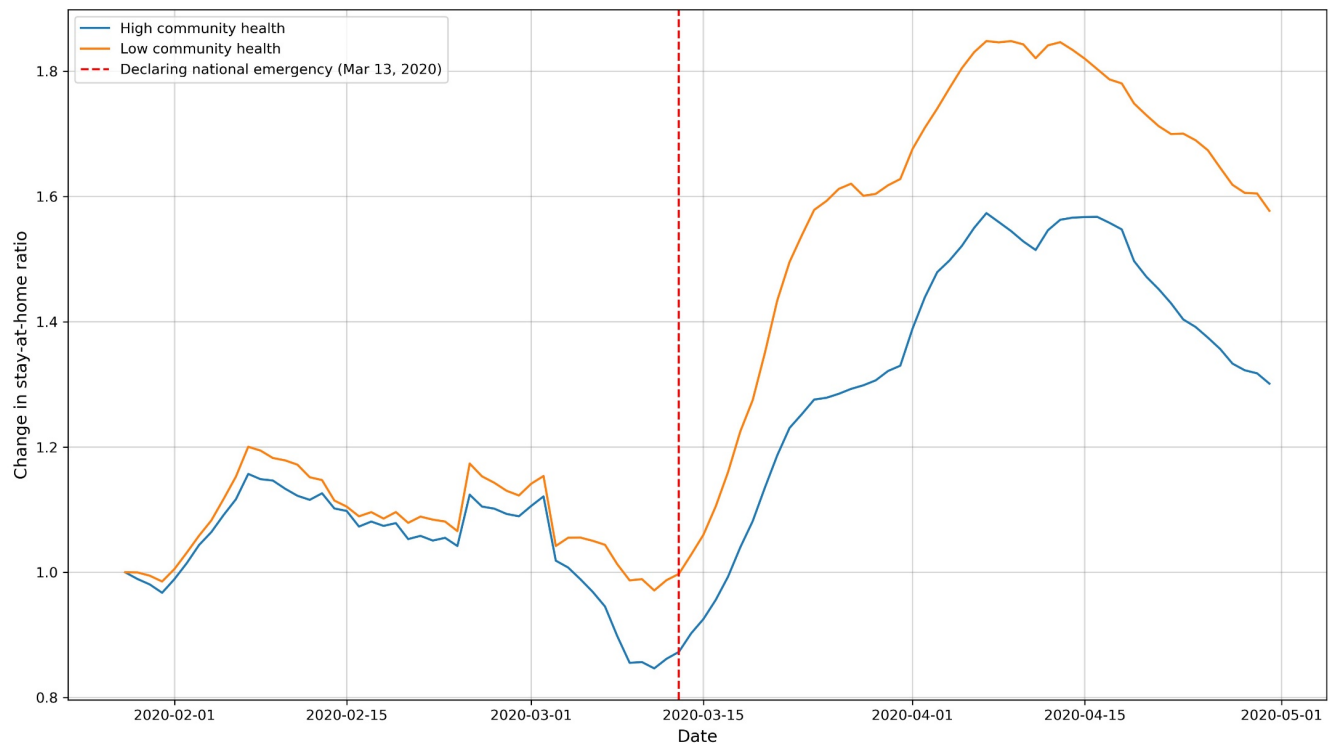

\section{Figure 16. Change in Stay Home, by Community health}

This figure show the different stay-at-home ratio trends for different levels of Community health index. The stay-at-home ratio is the number of devices not leaving home completely to the total number of devices. To mitigate the weekly cycle effect, we take the average stay-at-home ratio for the past week for each day. Counties with top quartile Community health index are classified into high index group, while bottom quartile are the low index group. The blue line represents the high index group, while the yellow line represents the low index group. We plot the relative change to the pre-pandemic level (Jan 29, 2020) for each group, respectively. 


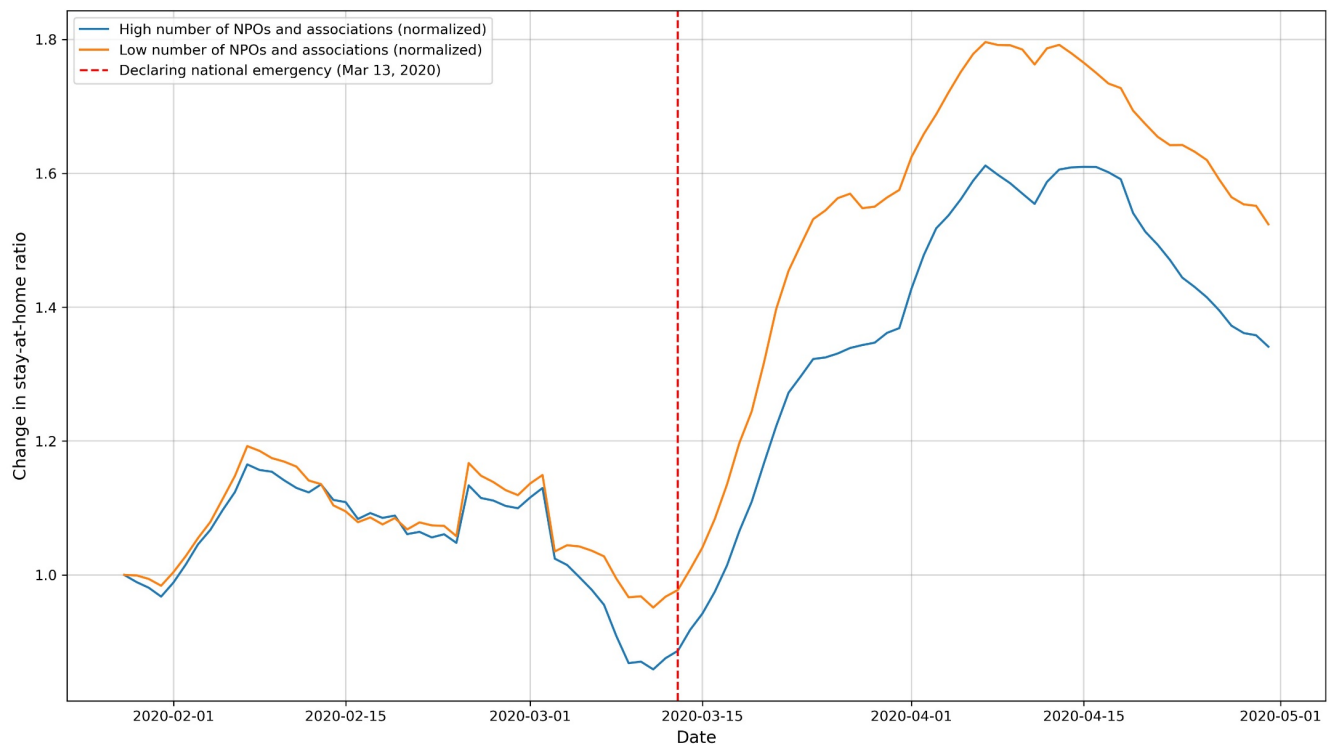

\section{Figure 17. Change in Stay Home, by Associations}

This figure show the different stay-at-home ratio trends for different levels of number of NPOs and associations (normalized). The stay-at-home ratio is the number of devices not leaving home completely to the total number of devices. To mitigate the weekly cycle effect, we take the average stay-at-home ratio for the past week for each day. We normalize the number of associations per 1,000 population and the number of NPOs per 1,000 population to the range of 0 to 1 , and then take the average to calculate this index. Counties with top quartile number of NPOs and associations (normalized) are classified into high index group, while bottom quartile are the low index group. The blue line represents the high index group, while the yellow line represents the low index group. We plot the relative change to the pre-pandemic level $(\operatorname{Jan} 29,2020)$ for each group, respectively. 


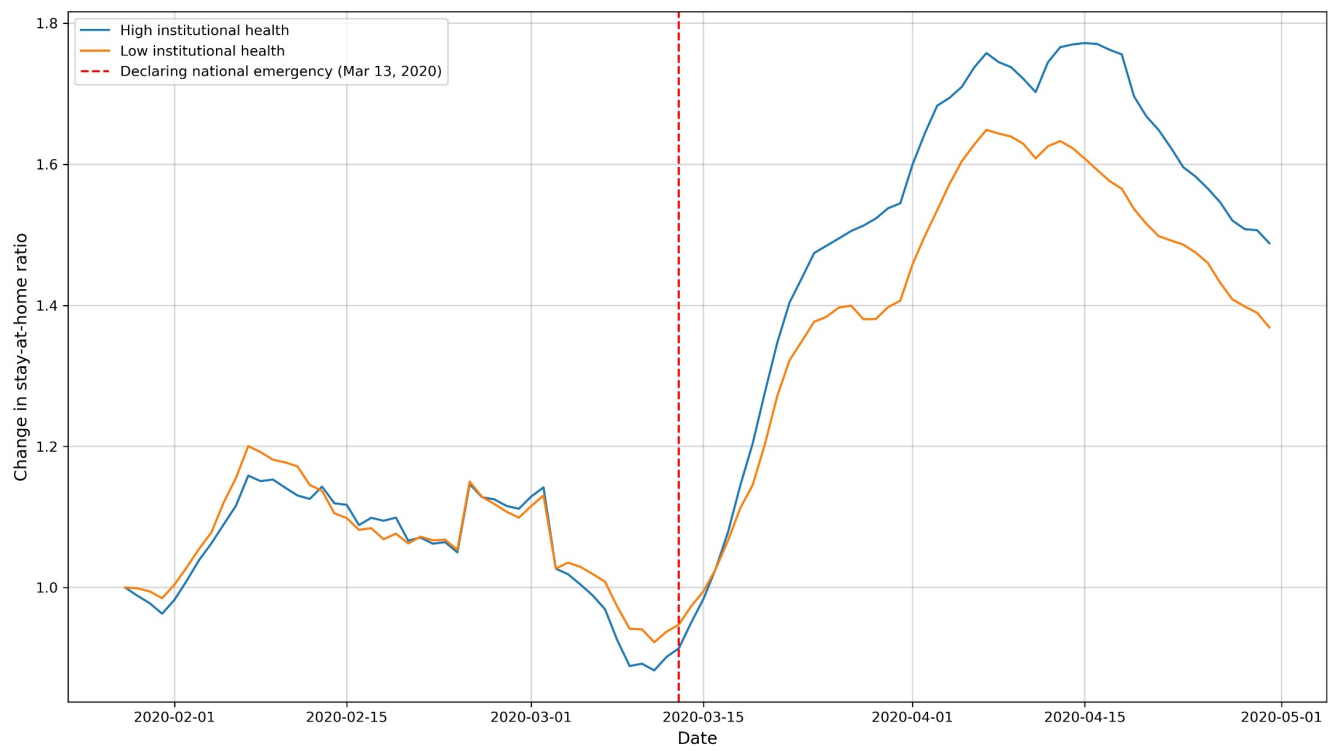

Figure 18. Change in Stay Home, by Institutional health

This figure show the different stay-at-home ratio trends for different levels of Institutional health index. The stay-at-home ratio is the number of devices not leaving home completely to the total number of devices. To mitigate the weekly cycle effect, we take the average stay-at-home ratio for the past week for each day. Counties with top quartile Institutional health index are classified into high index group, while bottom quartile are the low index group. The blue line represents the high index group, while the yellow line represents the low index group. We plot the relative change to the pre-pandemic level (Jan 29, 2020) for each group, respectively. 


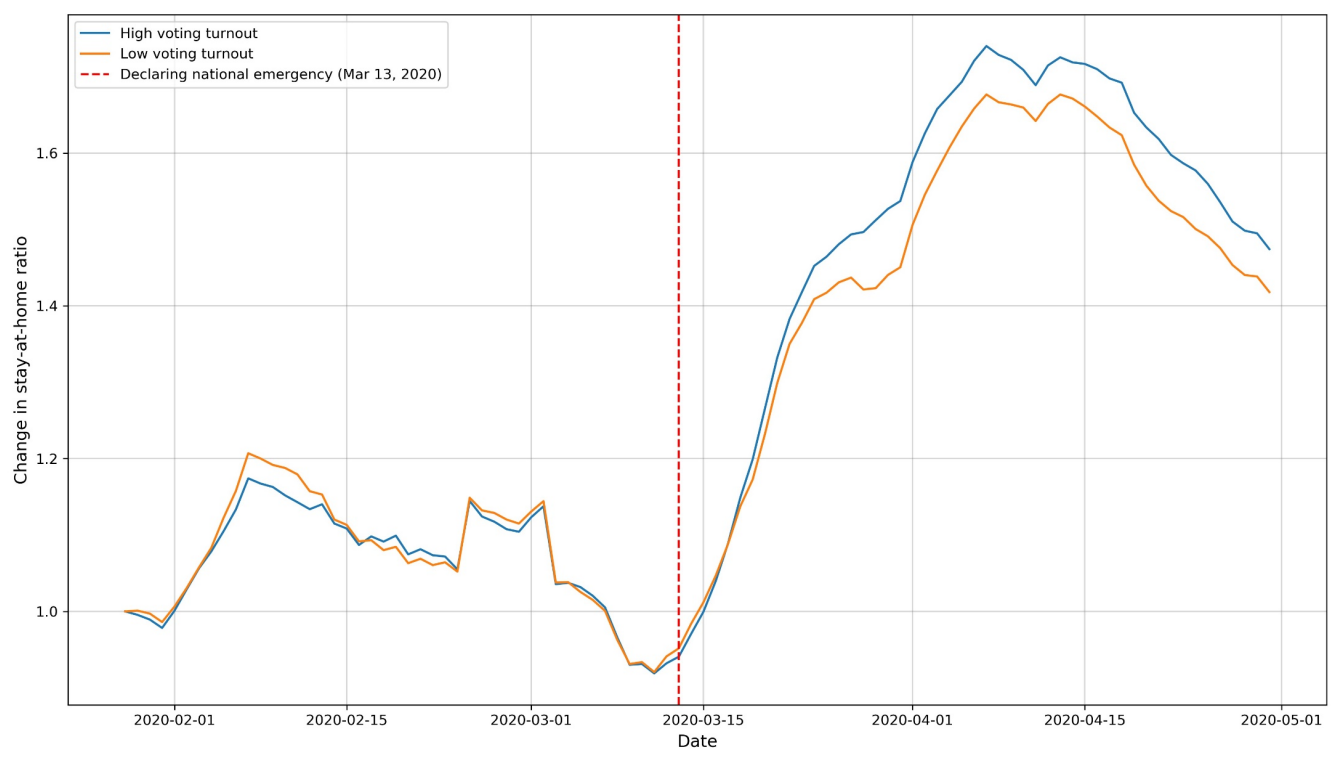

\section{Figure 19. Change in Stay Home, by Voting turnout}

This figure show the different stay-at-home ratio trends for different levels of voting turnout for the 2012 presidential election. The stay-at-home ratio is the number of devices not leaving home completely to the total number of devices. To mitigate the weekly cycle effect, we take the average stay-at-home ratio for the past week for each day. Counties with top quartile voting turnout are classified into high index group, while bottom quartile are the low index group. The blue line represents the high index group, while the yellow line represents the low index group. We plot the relative change to the pre-pandemic level (Jan 29, 2020) for each group, respectively. 


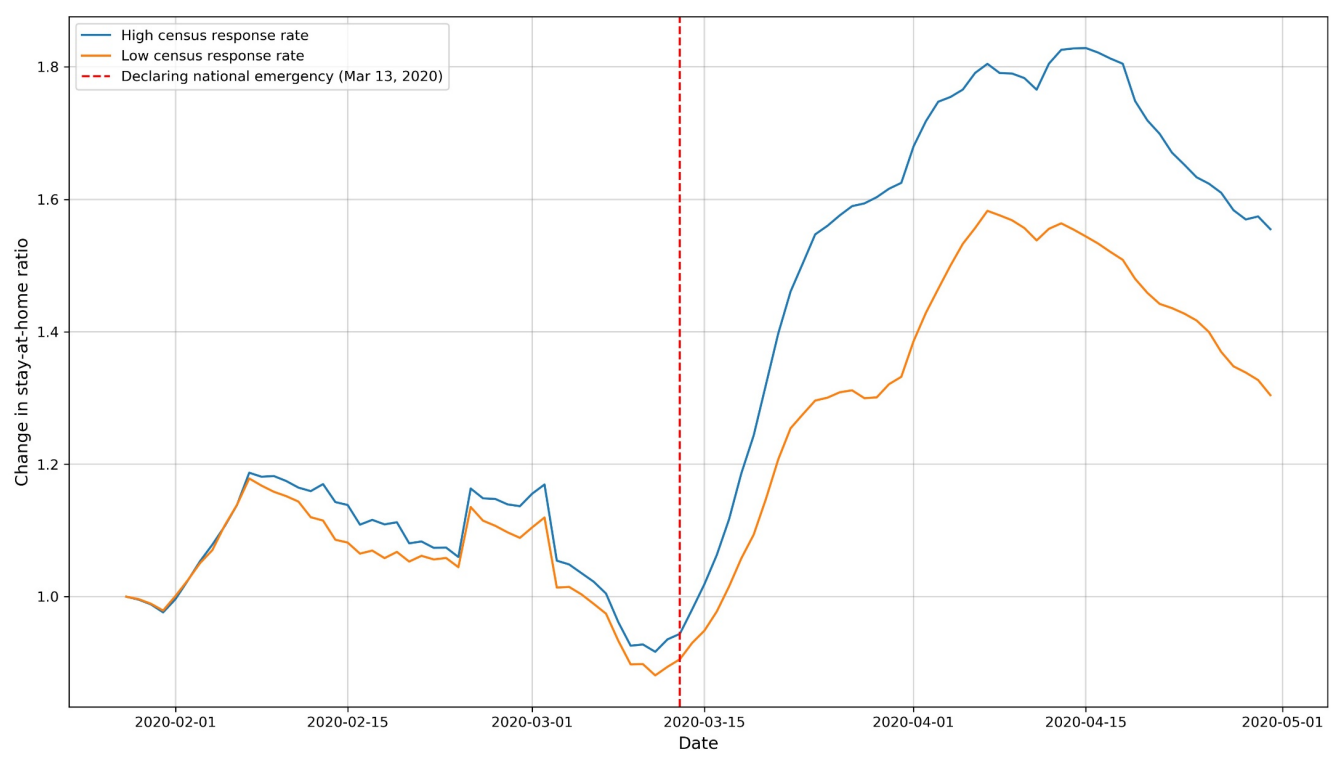

\section{Figure 20. Change in Stay Home, by Census response}

This figure show the different stay-at-home ratio trends for different levels of response rate to the 2010 census. The stay-at-home ratio is the number of devices not leaving home completely to the total number of devices. To mitigate the weekly cycle effect, we take the average stay-at-home ratio for the past week for each day. Counties with top quartile response rate are classified into high index group, while bottom quartile are the low index group. The blue line represents the high index group, while the yellow line represents the low index group. We plot the relative change to the pre-pandemic level (Jan 29, 2020) for each group, respectively. 


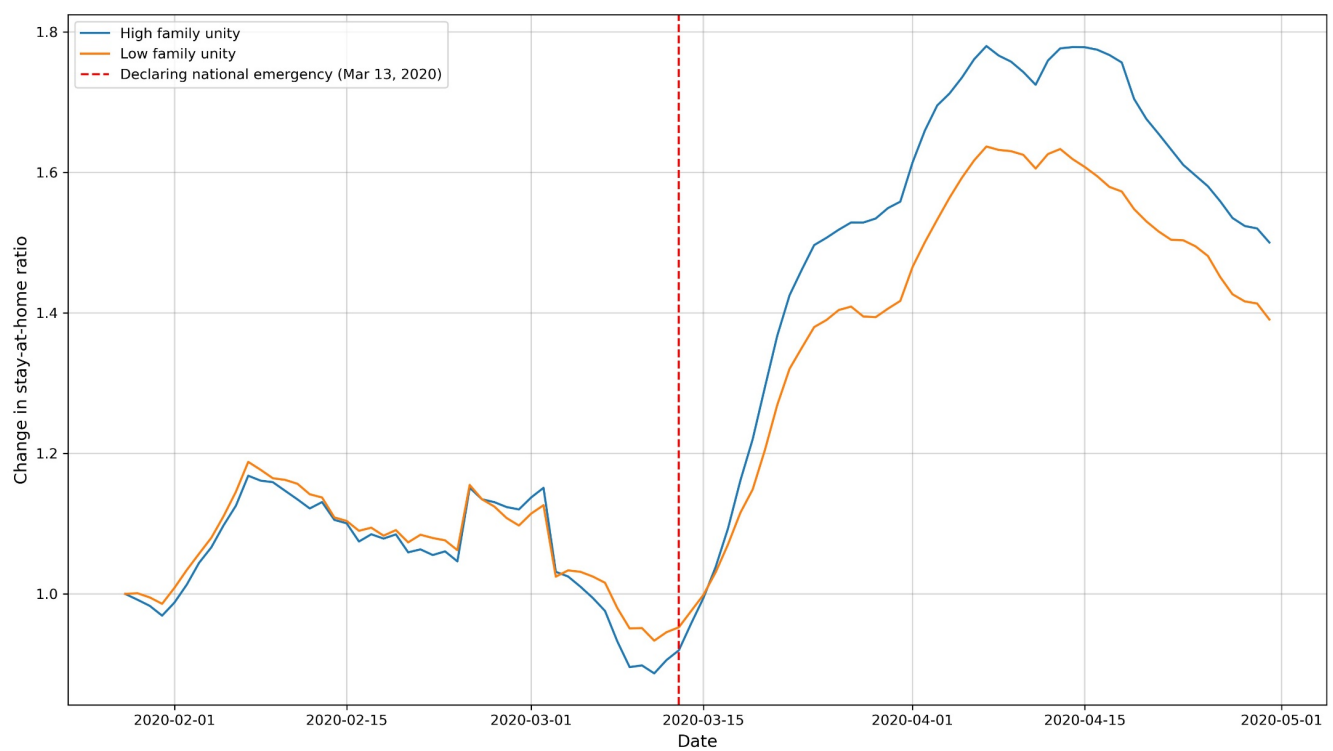

\section{Figure 21. Change in Stay Home, by Family unity}

This figure show the different stay-at-home ratio trends for different levels of Family unity index. The stay-at-home ratio is the number of devices not leaving home completely to the total number of devices. To mitigate the weekly cycle effect, we take the average stay-at-home ratio for the past week for each day. Counties with top quartile Family unity index are classified into high index group, while bottom quartile are the low index group. The blue line represents the high index group, while the yellow line represents the low index group. We plot the relative change to the prepandemic level (Jan 29, 2020) for each group, respectively. 